\title{
Human fibroblast-like synoviocyte isolation matter: a comparison between cell isolation from synovial tissue and synovial fluid from patients with rheumatoid arthritis
}

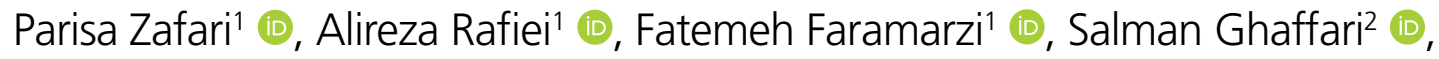 \\ Aref Hosseinian Amiri ${ }^{3}$ (D), Mahdi Taghadosi* ${ }^{4 *}$
}

\section{SUMMARY}

OBJECTIVE: Cell culture technology has become a popular method in the field of cell biology, pharmacology, and medical researches. Primary cells represent the normal physiological condition of human cells. Fibroblasts are the most common native cells of connective tissue that play a crucial role in the entire pathogenesis of various disorders, such as rheumatoid arthritis (RA). Fibroblast-like synoviocytes (FLSS), which overlie the loose connective tissue of the synovial sublining, are known to be the central mediators of joint damage. The most routine approach for the isolation of FLS is an enzymatic digestion of synovial tissue. This experimental study is designed to introduce an easy, fast, and high-throughput method compared with enzymatic digestion for isolation of FLS.

METHODS: The synovial tissue and synovial fluid (SF) samples were collected from eight patients with RA who underwent routine knee replacement surgery. Synovial tissue was incubated with collagenase VIII enzyme, while SF was washed with a similar volume of phosphatebuffered saline. The cells were further subcultured and stored based on the standard protocols. The purity of isolated synoviocytes was confirmed using flow cytometry analysis.

RESULTS: Isolation of FLS from SF was more successful with a faster rate, 3-5 days after culture. The morphological assessment and flow cytometry analysis confirmed the purity of SF-derived cells in passage 4.

CONCLUSIONS: SF could be a more accessible source of FLS than synovial tissue. Obtaining primary FLS from SF is a simple, fast, and cost-effective way to have a large-scale cell during a short time.

KEYWORDS: Cell culture. Cell isolation. Fibroblast-like synoviocyte. Synovium. Synovial fluid.

\section{INTRODUCTION}

Rheumatoid arthritis (RA) is a complex and multisystem disorder that primarily affects the synovial joints ${ }^{1,2}$. Fibroblast-like synoviocytes (FLSs) and macrophage-like synoviocytes (MLSs) are two main resident cells in the intimal layer of the synovial membrane, which play a central role in the joint pathology of RA ${ }^{3}$. Nevertheless, FLSs are the most common cell at the bone-pannus interface with a more abundant population than MLSs $^{4,5}$. The migration and invasion of FLS into cartilage and bone are a key event in synovial hyperplasia, resulting in cartilage destruction in patients with $\mathrm{RA}^{6,7}$. Activated FLSs produce a wide range of inflammatory mediators, which promote

\footnotetext{
${ }^{1}$ Mazandaran University of Medical Sciences, School of Medicine, Department of Immunology, Molecular and Cell Biology Research Center - Sari, Iran. ${ }^{2}$ Mazandaran University of Medical Sciences, Orthopedic Research Center - Sari, Iran.

${ }^{3}$ Mazandaran University of Medical Sciences, Imam Khomeini Hospital, Rheumatology Department - Sari, Iran.

${ }^{4}$ Kermanshah University of Medical Sciences, School of Medicine, Department of Immunology - Kermanshah, Iran.

*Corresponding author: mtaghad@gmail.com

Conflicts of interest: the authors declare there is no conflicts of interest. Funding: none.

Received on August 22, 2021. Accepted on August 29, 2021.
} 
the recruitment and activation of circulating and resident immune cells. Also, the migration of arthritis to unaffected joints has been attributed to the transmigration of FLSs ${ }^{8,9}$. Although there is still much to be learned about their resolution in RA disease, FLSs have sparked a lot of attention in recent studies. The culture and growth of FLSs is the first step for the investigation and analysis of these cells. At present, the synovium is the main and traditional source of FLS, and access to the synovium is feasible only during arthroplasty or arthroscopy surgery. In advanced RA, total joint arthroplasty (TJA) has been suggested as a successful intervention when optimal medical and supportive therapies have failed ${ }^{10,11}$. It has been reported that early and continuous use of biological and disease-modifying antirheumatic drugs (DMARDs) delays TJA ${ }^{12,13}$. Given the importance of FLS in RA pathology, there is a great need to find a reliable and repeatable source for quick access to them. As we know, the extraction of FLSs from synovium obtained during surgery is time-consuming and prone to contamination with microorganisms as well as needs a lot of materials. So, the establishment of an optimized procedure with low cost and shorter time compared with an enzymatic method is essential. In this study, for comparing the efficiencies of different isolation, we aimed to compare two currently being used FLS isolation methods to find a simple and effective procedure.

\section{Materials and reagents}

Dulbecco's modified Eagle medium: nutrient mixture F-12 (DMEM/F12)+PSF (penicillin, streptomycin, and fungizone) (Biosera) (for the digestion mixture), fetal bovine serum (FBS) (Biosera), 0.25\% trypsin-EDTA (Biosera), collagenase type VIII (Sigma C-2139), fluorochrome-labeled antibodies, cell culture flasks, dishes and tubes, and surgical blade (NO.17) were used.

\section{METHODS}

\section{Patients and tissue samples}

Human synovial tissue and synovial fluid (SF) were obtained from eight female patients with RA who underwent total knee arthroplasty in the Department of Orthopedics, Shafa Hospital, Sari, Mazandaran, with an average age of 58.8 \pm 9.66 years, ranging from 48 to 77 years. All patients fulfilled the 2010 RA classification criteria ${ }^{14}$. This study was approved by the Institutional Medical Ethics Committee of Mazandaran University of Medical Sciences (MAZUMS; IR.MAZUMS. REC.1398.1364), and informed consent was acquired from all patients before surgery.

\section{Cell culture}

\section{Synovium}

The synovial tissues were carried from the surgery department to the cell culture laboratory in a $50-\mathrm{ml}$ falcon tube containing 15-ml DMEM culture medium with $100 \mathrm{U} / \mathrm{ml}$ penicillin, 100 $\mathrm{U} / \mathrm{ml}$ streptomycin, and $1 \%$ amphotericin $\mathrm{B}$ as transport media and stored at $4^{\circ} \mathrm{C}$ before processing. Then, the collected tissues were, respectively, washed with phosphate-buffered saline (PBS) (pH 7.3-7.4), alcohol (75\%), and finally with PBS+100 U/ml penicillin, $100 \mathrm{U} / \mathrm{ml}$ streptomycin, and $1 \%$ amphotericin $\mathrm{B}$, each for a period of $2 \mathrm{~min}$. Tissues were minced into $1 \mathrm{~mm} \times 1$ $\mathrm{mm}$ pieces with the help of sterile BP blade No. 17 in a sterilized Petri dish containing DMEM media and then incubated with collagenase VIII for $2 \mathrm{~h}$ at $37^{\circ} \mathrm{C}$ in a shaker incubator to promote isolation of FLS. After incubation time, cell pellets were harvested by centrifugation at $1000 \mathrm{~g}$ for $10 \mathrm{~min}$. Then, pellets were suspended in DMEM supplemented with $10 \%$ (vol/vol) heat-inactivated FBS, $100 \mathrm{U} / \mathrm{ml}$ penicillin, and 100 $\mathrm{U} / \mathrm{ml}$ streptomycin and placed in a $\mathrm{T}-25$ flask at $37^{\circ} \mathrm{C}$ with $5 \%$ $\mathrm{CO}_{2}$ in a humidified atmosphere. After $48 \mathrm{~h}$, the medium was changed, and the isolation of cells from synovial tissues was checked every day. The medium was changed twice a week.

\section{Synovial fluid}

After collection of SF in a 15-ml falcon tube containing anticoagulant, it was diluted twice with sterile PBS and centrifuged at $400 \mathrm{~g}$ for $10 \mathrm{~min}$. Harvested pellets were suspended in DMEM with $10 \%$ FBS and antibiotics containing $100 \mathrm{U} / \mathrm{ml}$ penicillin and $100 \mathrm{mg} / \mathrm{ml}$ streptomycin. The cells were placed in T-25 flasks and incubated under the standard condition at $37^{\circ} \mathrm{C}$ with $5 \% \mathrm{CO}_{2}$ with saturated humidity. Following the 48 $\mathrm{h}$ incubation, fresh DMEM was added to the cells. The culture medium was refreshed every 3-4 days.

SF and synovial tissue culture processing steps are shown in Figure 1.

\section{Identification of FLS by flow cytometry}

FLSs at passage 4 were identified by flow cytometry. The purity of FLS was checked for the presence of MLS. The cells were stained with the following antibodies: fluorescein isothiocyanate (FITC)-conjugated anti-CD68, phycoerythrin (PE)conjugated anti-CD14 antibody, and allophycocyanin (APC)conjugated anti-CD90.

\section{RESULTS}

The results showed that three of eight primary cultures of FLS by enzymatic digestion method were successful. The median 
time to the presence of the first cells was 15 days, and they reached $70-80 \%$ of confluency around $30-35$ days of culture. The remaining tissue samples were discarded if any cells were observed after 30 days. In contrast, cell isolation of all SF samples was successful, and the first cells were seen after about 3-4 days of culture. Getting $70-80 \%$ of confluency was dependent on the initial volume of SF.

\section{Morphology of FLS cells}

The cells were monitored for morphological assessment after the first day of their presence in the T-25 flask. Most of the cell population were spindle-shaped fibroblast, even in passage 0 ; however, few number of round to spherical shape, stellate-shaped, and epithelioid-shaped cells were also observed, especially in initial passages (Figure 2). Overall, isolated FLSs from synovium showed more similarity in shape in passages 1-3 compared with those from SF. It should be mentioned that the homogeneity of cells was different from one sample to another but all get to purity from passages 3 and 4 onward.

\section{Percentage of FLS}

Isolated synovial cells from synovium and SF were evaluated by flow cytometry at passage 4 . We found a similar percentage of positive cells in specific markers in both procedures used after passage 4.

Overall comparison between the two methods is summarized in Table 1.

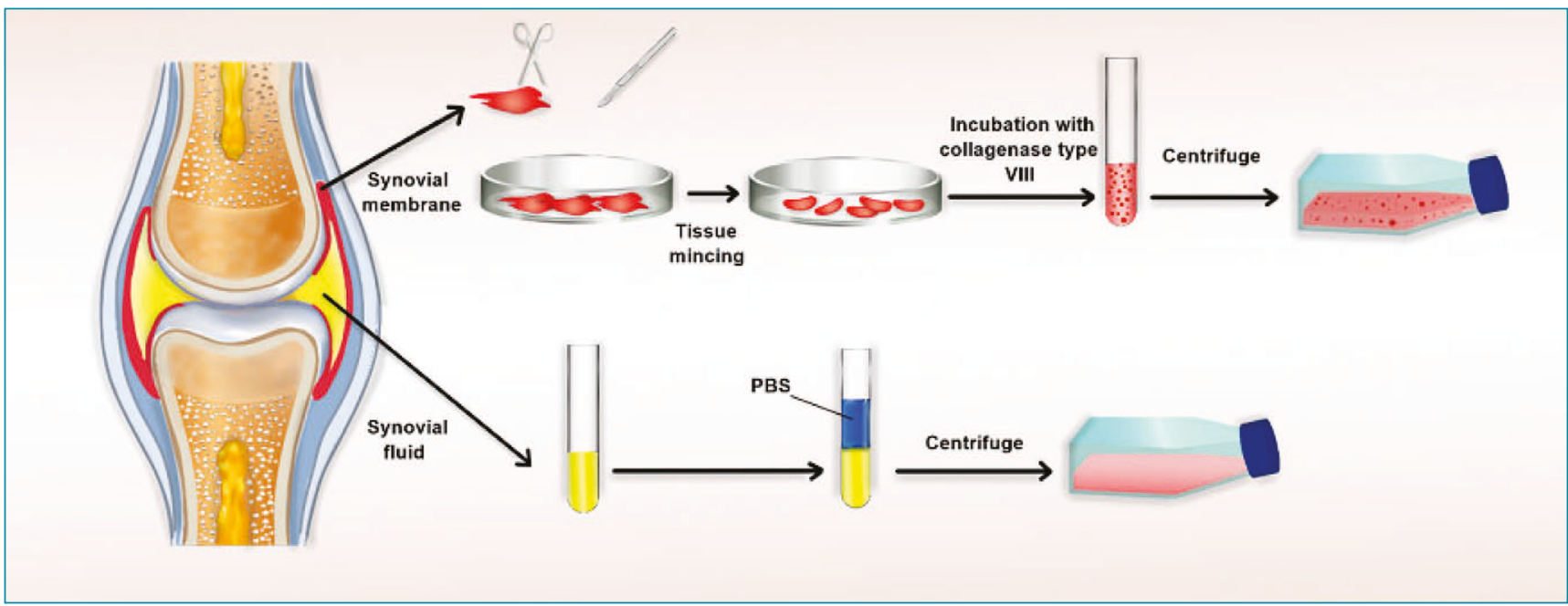

Figure 1. Schematic illustration of synovial fluid and synovial tissue culture processing steps.

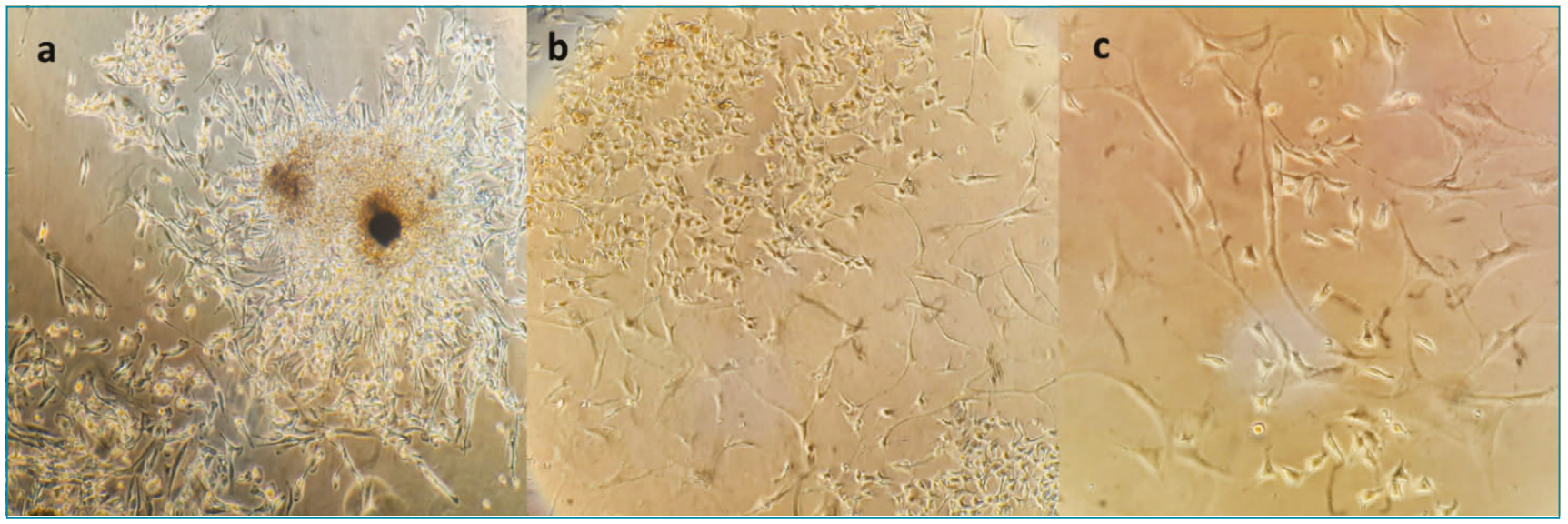

Figure 2. Light microscopic features of synovial fluid and synovial tissue culture. Cell outgrowth from synovial tissue on days 15-25 (a) (100x), a mixture of spindle-shaped and spherical shape fibroblasts with different size in passage 0 from synovial tissue (b) (100x) and synovial fluid (b) (400x). 
Table 1. Comparison of important characteristics between two isolation methods.

\begin{tabular}{l|c|c|c|c|c|c} 
FLS source & Volume & $\begin{array}{c}\text { Sample } \\
\text { preparation } \\
\text { time }\end{array}$ & $\begin{array}{c}\text { Primary } \\
\text { incubation }\end{array}$ & $\begin{array}{c}\text { Required } \\
\text { materials }\end{array}$ & $\begin{array}{c}\text { Number of } \\
\text { days to see } \\
\text { the first cell }\end{array}$ & $\begin{array}{c}\text { Getting to } \\
95 \% \text { purity }\end{array}$ \\
\hline Synovial tissue & $1 \mathrm{~cm}^{2}(1 \mathrm{mg})$ & $3.5-4 \mathrm{~h}$ & + & $\begin{array}{c}\text { Digestion enzyme, } \\
\text { PBS, alcohol }\end{array}$ & $15-25$ days & Passage 3 \\
\hline Synovial fluid & $500 \mu \mathrm{l}$ (minimum) & $20 \mathrm{~min}$ & - & $\begin{array}{c}\text { Anticoagulant, } \\
\text { PBS }\end{array}$ & $3-5$ days & $\begin{array}{c}\text { Passages } 4 \\
\text { and 5 }\end{array}$ \\
\hline
\end{tabular}

PBS: phosphate-buffered saline.

\section{DISCUSSION}

Isolation of primary cell lines is required for researchers to investigate the morphological, functional, and cellular characteristics of a special tissue ${ }^{15,16}$. Nevertheless, a single-standard protocol has not yet been optimized for the isolation of many cells, especially recently discovered ones. FLSs were recently proven to be key players of observed inflammation in RA context ${ }^{17,18}$. These cells locate inside joints in the synovium and are involved in pannus formation, a hallmark pathological change in patients with $\mathrm{RA}^{19-21}$. Recent advances in the treatment of rheumatologic disorders have resulted in a reduction of access to synovial tissues by investigators ${ }^{22}$. Accordingly, it is essential to find a more proximal source of FLSs than the replaced joints during arthroplasty. In this study, we readily extracted adherent fibroblast cells from SF compared with synovial tissues. Also, flow cytometry analysis of the SF-derived cells confirmed the phenotype of FLS cells. We found that FLS does not migrate from all synovial tissues, but FLS extraction from all SF samples was successful. However, extracted cells from SF were more heterogeneous in initial passages than those from synovial tissue, but in the following, they reach to a similar phenotype like synovial tissue-derived cells. These results are in the same direction as those obtained by Stebulis et al. who indicated that FLS isolation from SF can facilitate the study of synovial cells when synovial tissues are not available. They found that both SF- and tissue-derived FLS are the same in functional and cellular measures such as the presence of some specific enzymes and production of inflammatory mediators ${ }^{23}$. Moreover, Ahn et al. reported that there is no significant difference between the invasive capacity of the two FLS types and that both of them are identical in surface markers ${ }^{24}$. Neidhart et al. demonstrated that SF-derived FLSs mediate cartilage destruction similar to tissue-derived ones ${ }^{25}$. These reports are in agreement with our results regarding the identical characteristics of extracted FLSs from both methods.

\section{CONCLUSIONS}

We found that the extraction of FLS from synovial tissues is not $100 \%$, and FLS isolation from SF is the most convenient and effective method. The use of 500- $\mu \mathrm{l} \mathrm{SF}$ is sufficient to get a higher number of FLS with a shorter time and lower cost of cultivation than synovial tissues. These data may support the selection of FLS isolation from SF for downstream analysis.

\section{ACKNOWLEDGMENTS}

This work was partially supported by grants from Mazandaran University of Medical Sciences (MAZUMS) (IR.MAZUMS. REC.1398.1364) and Kermanshah University of Medical Sciences (KUMS) (990522).

\section{AUTHORS' CONTRIBUTIONS}

PZ: Conceptualization, Data curation, Investigation, Methodology, Writing - original draft, Writing - review $\&$ editing. AR: Investigation, Writing - review \& editing. FF: Formal analysis. SG: Investigation, Methodology. AH: Investigation, Methodology. MT: Conceptualization, Data curation, Investigation, Methodology, Writing - original draft, Writing - review \& editing.

\section{REFERENCES}

1. Guo Q, Wang Y, Xu D, Nossent J, Pavlos NJ, Xu J. Rheumatoid arthritis: pathological mechanisms and modern pharmacologic therapies. Bone Res. 2018;27(6):15. https://doi.org/10.1038/ s41413-018-0016-9
2. Mellado M, Martínez-Muñoz L, Cascio G, Lucas P, Pablos $\mathrm{JL}$, Rodríguez-Frade JM. T cell migration in rheumatoid arthritis. Front Immunol. 2015;6:384. https://doi.org/10.3389/ fimmu.2015.00384 
3. Yang $X$, Chang $Y$, Wei $W$. Emerging role of targeting macrophages in rheumatoid arthritis: focus on polarization, metabolism and apoptosis. Cell Prolif. 2020;53(7):e12854. https://doi.org/10.1111/cpr.12854

4. Tu J, Hong W, Zhang P, Wang X, Körner H, Wei W. Ontology and function of fibroblast-like and macrophage-like synoviocytes: how do they talk to each other and can they be targeted for rheumatoid arthritis therapy? Front Immunol. 2018;9:1467. https://doi.org/10.3389/fimmu.2018.01467

5. Jung SM, Kim KW, Yang CW, Park SH, Ju JH. Cytokine-mediated bone destruction in rheumatoid arthritis. J Immunol Res. 2014;2014:263625. https://doi.org/10.1155/2014/263625

6. Bartok B, Firestein GS. Fibroblast-like synoviocytes: key effector cells in rheumatoid arthritis. Immunol Rev. 2010;233(1):23355. https://doi.org/10.1111/j.0105-2896.2009.00859.x

7. Ostrowska M, Maśliński W, Prochorec-Sobieszek M, Nieciecki M, Sudoł-Szopińska I. Cartilage and bone damage in rheumatoid arthritis. Reumatologia. 2018;56(2):111-20. https://doi. org/10.5114/reum.2018.75523

8. Bustamante MF, Garcia-Carbonell R, Whisenant KD, Guma $M$. Fibroblast-like synoviocyte metabolism in the pathogenesis of rheumatoid arthritis. Arthritis Res Ther. 2017;19(1):110. https://doi.org/10.1186/s13075-017-1303-3

9. Nevius E, Gomes AC, Pereira JP. Inflammatory cell migration in rheumatoid arthritis: a comprehensive review. Clin Rev Allergy Immunol. 2016;51(1):59-78. https://doi.org/10.1007/ s12016-015-8520-9

10. Lee JK, Choi $\mathrm{CH}$. Total knee arthroplasty in rheumatoid arthritis. Knee Surg Relat Res. 2012;24(1):1-6. https://doi.org/10.5792/ ksrr.2012.24.1.1

11. Danoff JR, Moss G, Liabaud B, Geller JA. Total knee arthroplasty considerations in rheumatoid arthritis. Autoimmune Dis. 2013;2013:185340. https://doi.org/10.1155/2013/185340

12. Jämsen E, Virta LJ, Hakala M, Kauppi MJ, Malmivaara A, Lehto MUK. The decline in joint replacement surgery in rheumatoid arthritis is associated with a concomitant increase in the intensity of anti-rheumatic therapy: a nationwide register-based study from 1995 through 2010. Acta Orthop. 2013;84(4):331-7. https://doi.org/10.3109/17453674.2013.810519

13. Ragab OM, Zayed HS, Abdelaleem EA, Girgis AE. Effect of early treatment with disease-modifying anti-rheumatic drugs and treatment adherence on disease outcome in rheumatoid arthritis patients. The Egyptiam Rheumatologist. 2017;39(2):6974. https://doi.org/10.1016/j.ejr.2016.11.004

14. Kay J, Upchurch KS. ACR/EULAR 2010 rheumatoid arthritis classification criteria. Rheumatology (Oxford). 2012;51 Suppl 6:vi5-9. https://doi.org/10.1093/rheumatology/kes279
15. Patil $R$, Kale $A D$, Mane $D R$, Patil $D$. Isolation, culture and characterization of primary cell lines of human buccal mucosal fibroblasts: a combination of explant enzamytic technique. J Oral Maxillofac Pathol. 2020;24(1):68-75. https://doi. org/10.4103/jomfp.JOMFP_282_19

16. Weigand A, Boos AM, Tasbihi K, Beier JP, Dalton PD, Schrauder $M$, et al. Selective isolation and characterization of primary cells from normal breast and tumors reveal plasticity of adipose derived stem cells. Breast Cancer Res. 2016;18(1):32. https:// doi.org/10.1186/s13058-016-0688-2

17. Takeuchi Y, Hirota K, Sakaguchi S. Synovial tissue inflammation mediated by autoimmune T cells. Front Immunol. 2019;10:1989. https://doi.org/10.3389/fimmu.2019.01989

18. Chang SK, Gu Z, Brenner MB. Fibroblast-like synoviocytes in inflammatory arthritis pathology: the emerging role of cadherin-11. Immunol Rev. 2010;233(1):256-66. https://doi. org/10.1111/j.0105-2896.2009.00854.x

19. You S, Yoo SA, Choi S, Kim JY, Park SJ, Ji JD, et al. Identification of key regulators for the migration and invasion of rheumatoid synoviocytes through a systems approach. Proc Natl Acad Sci U S A. 2014;111(1):550-5. https://doi.org/10.1073/ pnas. 1311239111

20. Nygaard G, Firestein GS. Restoring synovial homeostasis in rheumatoid arthritis by targeting fibroblast-like synoviocytes. Nature Rev Rheumatol. 2020;16(6):316-33. https://doi. org/10.1038/s41584-020-0413-5

21. Cheng $L$, Wang $Y, W u$ R, Ding $T$, Xue $H$, Gao $C$, et al New insights from single-cell sequencing data: synovial fibroblasts and synovial macrophages in rheumatoid arthritis. Front Immunol. 2021;12:709178. https://doi.org/10.3389/ fimmu.2021.709178

22. Johnson BK, Goodman SM, Alexiades MM, Figgie MP, Demmer RT, Mandl LA. Patterns and associated risk of perioperative use of anti-tumor necrosis factor in patients with rheumatoid arthritis undergoing total knee replacement. J Rheumatol. 2013;40(5):617-23. https://doi.org/10.3899/jrheum.121171

23. Stebulis JA, Rossetti RG, Atez FJ, Zurier RB. Fibroblastlike synovial cells derived from synovial fluid. J Rheumatol. 2005;32(2):301-6. PMID: 15693092

24. Ahn JK, Kim H, Lee J, Bae EK, Cha HS, Koh EM. Phenotypic characterization and invasive properties of synovial fluid-derived adherent cells in rheumatoid arthritis. Inflammation. 2008;31 (6):365-71. https://doi.org/10.1007/s10753-008-9087-x

25. Neidhart M, Seemayer CA, Hummel KM, Michel BA, Gay RE, Gay S. Functional characterization of adherent synovial fluid cells in rheumatoid arthritis: destructive potential in vitro and in vivo. Arthritis Rheum. 2003;48(7):1873-80. https://doi. org/10.1002/art.11166 